\title{
DIVERSITY MANAGEMENT AS A HUMAN RESOURCE MANAGEMENT STRATEGY TO COMPETE IN ORDER ERA INDUSTRIAL REVOLUTION 4.0
}

\author{
Ade. Parlaungan Nasution ${ }^{1,}$ Ramdani $^{2}$ \\ ${ }^{1}$ Sekolah Tinggi Ilmu Ekonomi Labuhan Batu, adenasution@gmail.com \\ ${ }^{2}$ University of Riau Islands, ramdanidani146@gmail.com
}

\begin{abstract}
Development of the rapidly growing business and with the emergence of new competitors requires companies to invest by the development and regeneration of the employees. Management of human resources management requires diversity as one of the keys to win the competition. Diversity is one of the factors that strengthen the company's position as a company. However, the permasalahaan is not all companies, even though multinational companies can implement diversity management in human resources management. It is therefore necessaryanalytical explanation of the concept of diversity management that can be applied within a company, It manages well with the diversity that exists within a company, is expected to prevent conflicts and to maximize the achievement of the ability to compete with the advantages that can be gained from the diversity of existing human resources.
\end{abstract}

Keywords: Diversity Management, Human Resources

\section{PRELIMINARY}

The development of technology and the ease of accessing information in the era of industrial revolution 4.0 makes the world gets smaller and making the business activities carried on like without any geographical limitation. As a consequence the company or organization has to deal with different people and different perspectives, as well as the need to prepare for what should be done to manage the business, both local and global businesses. According beck (2016) in the era of industrialization, new technology has turned the previous technology quickly. In line with this, the adoption of Internet-based technology and artificial artificer has been used as a component of formation of the competitive ability of the company by various business sectors. Roaman (2017).

A company is said to have the ability to compete is when the company has something that is not or something better than other companies and do something that is not able to be done by other firms (Susanto, 2015). Increasingly diverse business challenges forcing companies to transform in order to maintain the existence and improve competitiveness (Mey, 2016). Efficiency and productivity as a way to maintain the existence can be achieved through the quality of human resources. 
Development of the rapidly growing business and with the advent of new competitors such as requiring companies to invest in the development and regeneration of the human resources. Regeneration employee needs to be done by the company to create a healthy corporate environment in terms of the composition of age or position (Vin, 2014). Management of human resources management requires a so-called diversity management as one of the keys to win the competition (Rey, 2016). Diversity is one of the factors that strengthen the company's position as a company (Tang \& Khy, 2017). This diversity provides a different view to expanding the knowledge and approach to the industry, as well as enterprise customers are also diverse.

Although it can not be denied that the increasing diversity of human resources in a company also has a negative side, but the company could benefit from diversity through strategic management of the diversity of the human resources (Mathis and Jackson, 2010). Of course, the expected benefits are not automatically acquired the company, it takes an understanding and proper management with regard to the diversity of human resources, particularly in the industrial era 4.0 this.

But the problem is that not all companies, even though multinational companies can implement diversity management in human resources management. This is ultimately the company's inability to manage diversity in the workplace / enterprise can lead to various problems in the future (Solvy, 2012). For example, the conflict in the location of the power plant project Java 7 due to the beating of a local worker sparked riots on 9 September 2018 (www.news.detik.com, 2018). The next conflict between the management of PT Garuda Indonesia and Garuda Pilots Association pilots strike that sparked a Garuda Indonesia Airways on July 28, 2011 (www.kompasiana.com 2011). Both cases show the diversity is not managed by the existing workforce at both companies.

Referring to both the above cases, the implementation of diversity management (diversity) in Indonesia, it is very necessary, not only caused by the increasing number of multinational companies in Indonesia, also due to the diversity that comes from Indonesia itself. Through this article will explain theoretically the concept of diversity management and how it is applied in the management of human resources in a company. It manages well with the diversity that exists in a company, is expected to prevent conflicts and to maximize the achievement of competitive ability of the company through the advantages that can be gained from the diversity of existing human resources.

\section{METHODOLOGY}


This study is a research library (Library R engine) or Reader Review. Library Research by Kartini Kartono (1996) is a study of some of the literature in the form of books, magazines, bulletins, newspapers, the internet, the results of seminars and other resources related to the problem are formulated. In this literature study presented issues related to diversity management within a company as well as analytical exposure of the concept of diversity management that can be applied in a company. The data were derived from theoretical literature study, in association with the title raised in the study. In this case,

\section{DISCUSSION}

\section{Competing Ability Achievement Through Corporate Human Resources Management Diversity Management Uses}

The competitive ability of the company to appear when a company can produce the same product with the resulting competitors with lower costs (cost advantage), or products / services that are different and better than that produced by its competitors (differentation advantage) (Porter, 2012). The ability to compete will enable the company has more value can earn higher profits.

\section{Diversity As A Human Resource Management Perspective}

Diversity can be defined literally as the difference. The differences are often discussed meruapakan differences in terms of ethnicity, skin color, gender differences, and many more. Allard (2002), confirms in a very broad sense that includes within it is the level of social, cultural, physical, and environmental differences among many people that will affect the way they think and act or behave. Thomas and Ely (1996), provide affirmative view of diversity as a variety of perspectives and approaches to work are taken of each individual in the identity and group shows. It is by Allard (2002), said about the complexities of the culture that can increase the difficulty in processing the difference (diversity) in the company.

Implementation of diversity management by companies should begin with the culture and values that need to be understood by all members in the company. Companies should be able to care and give great attention to human resources owned by observing and devise strategies for developing and managing human resources (Robert, 2015). Human resources management strategy adopted by the company should also be aligned to the vision and mission, strategy and corporate culture (Boney, 2014). One form of diversity management that can be applied, namely a culture of active involvement of employees. 


\section{Implementation of Diversity Management in Human Resource Management}

Globlisasi era characterized by increasingly competitive business environment, therefore we need a proper business strategy that has the ability to compete so that the company can survive in the competition. Human resource management broadly faced with two kinds of diversity (cultural and personal) is requested to take a strategic decision (Brickson, 2010).

The company will benefit from having diversity manajmen namely creativity and innovation, as people from different backgrounds will have different viewpoints on an issue. Diverse groups would have broader experience base in the pass approach a problem (Born 2011). When managed effectively, they will generate more solutions than a homogeneous group so that the company can achieve competitive advantages (Neny, 2015). Companies that provide opportunities for diverse employees will have a competitive advantages and attractive to employees who have the highest qualifications. When employees believe that their differences are not only tolerated, but rewarded, they will be more loyal, productive, and committed (Subhan, 2016). This is consistent with the statement Knouse et al (2012) that the implementation of diversity management company can improve problem solving through knowledge resources because with the diversity of the members can provide more information, new approaches, perspectives richer on solving the problem of the organizations and other benefits that create.

In this regard, the main priorities of a company in achieving its ability to compete is to develop human resources with superior skills. This process began with an innovative recruitment with extensive coverage to be able to recruit individuals who have qualities and abilities suitable to be placed in the position being offered (Alen, 2014). The company seeks to recruit qualified individuals from many different backgrounds to join the company. Bleijenbergh, Peters and Poutsma (2010) mengemukan that diversity management is an inclusive approach that begins with the recruit or attract different people into the company, then propose and establish a broader understanding of the different individuals.

Furthermore, in application of the principle of diversity management, selection is done by the company after the stage of recruiting candidates. In this event, prospective employees can be taken into a mentoring program that apprenticeship in accordance with the educational background to then be taken into the evaluation process of the experiment (Melani 2013). When employees have passed the stage of the selection and evaluation of the 
employees had the opportunity to become permanent employees (Melani, 2013). Through this process, the company has provided career opportunities as possible to employees without discrimination by considering the competence, performance, and corporate needs.

Further, in the management of human resources using the principles of diversity management, companies can conduct education and training that can be tailored to the needs and conditions of each company. This is according to Wheeler (2014) which states that the definition of diversity training varies from one organization to another and often how organizations define diversity training is strongly influenced by the diversity that is understood within the organization.

Furthermore prusahaan need to set the policy on the promotion and compensation to employees. Bateman (2007) stated that managing diversity requires a firm commitment to regularly review the policies and practices related to recruitment, career development, promotion and remuneration to ensure that all employees and prospective employees have access to opportunities and equal treatment, without gender discrimination, ethnic, religious or social status.

\section{Possible Obstacles and Solutions Guide In the Implementation of Diversity Management in Human Resource Management}

In applying diversity management companies to be able to achieve a competitive edge sometimes encounter some obstacles or problems, whether it came from within and outside the company. The obstacles prusahaan should become a reference for evaluating policies related to human resource management using the concept of diversity management. Ultimately any problems can be resolved so that the constraints in the implementation of the concept of diversity management in human resources management can be overcome. The obstacles are as follows.

The failure of the implementation of diversity policies can be caused by the unpreparedness of the members organiasasi sehigga failed in making the transition or the transition from monolothic organizational framework leading to the risk associated with serious public and financial implications of a negative basis (Allen and Montgomery, 2001).

Furthermore, kOLICY often planned incomplete and unsustainable in its implementation. Then the emergence of an imbalance between the ratio of female workers and male then the gap between employees out (retired) and entered in the company as well as facilities for pumping. Furthermore, government policies and the establishment of the 
ASEAN Free Trade with the increasingly fierce competition and the economic situation changes very quickly is one of the challenges.

To resolve the problems, should the company can start by adjusting the ratio of employment in the company and provides the opportunity for women to occupy a position / positions in particular. For the company's current facilities themselves have started to prepare a budget to build a room for pumping. Further, the company also had to put respect for the welfare of employees in a high position by providing medical facilities for employees and their families and paskakerja program that can give peace in the future. Human Resources Management System in the company can be based on the competence and the need for personnel in all work units.

\section{CONCLUSION}

The increasing diversity of human resources in a company brings a positive side and has a negative side. Companies can benefit from diversity through strategic management of human resources diversity. But the problem is that not all companies, even multinationals seklipun can implement diversity management in human resources management. This is ultimately the company's inability to manage diversity in the workplace / enterprise can lead to various problems in the future. The company will benefit from having diversity manajmen namely creativity and innovation, as people from different backgrounds will have different viewpoints on an issue. In applying diversity management companies to be able to achieve a competitive edge sometimes encounter some obstacles or problems, whether it came from within and outside the company. Various constraints should become a reference company to evaluate policies related to human resource management using the concept of diversity management.

\section{LITERATURE}

https://news.detik.com/berita/d-4204418/pukul-pekerja-lokal-tka-asal-china-diamankan-polisi 